\title{
FOUR-CORNER BLADDER AND URETHRAL RETROPUBIC SUSPENSION VERSUS ANTERIOR COLPORRHAPHY IN THE CORRECTION OF STRESS URINARY INCONTINENCE WITH URETHROCYSTOCELE 3-4. RANDOMIZED CLINICAL TRIAL
}

\author{
V. SCOTTO DI PALUMBO \\ DIVISIONE DI OSTETRICIA E GINECOLOGIA \\ OSPEDALE SAN CAMILLO DE LELLIS - RIETI - ITALY \\ Keywords: Female stress incontinence; Nichols' surgical procedure; \\ Randomized clinical trial; Raz surgical technique; urethrocystocele.
}

\begin{abstract}
In this study we compared, in a prospective randomized trial, the results, in terms of anatomic and functional correction, of two procedures for Stress urinary incontinence (SUI) with cystocele 3-4: four-corner retropubic correction versus anterior repair with medial duplication of the pubocervical fascia and pubourethral ligaments plication. From June 1996 through April 2000, 80 patients affected by SUI type 1 and 2 according to Blaivas with urethrocystocele of 3 or 4 degrees according to the halfway system were randomly assigned to one of the following treatments (randomization 2:1): -1. Anterior colporrhaphy according to Nichols (52 women); -2. Four-corner bladder and urethral retropubic suspension according to Raz (28 women). The follow-up time of patients varied from 280 to 1670 days. The SUI relapse occurred in 26.9\% of patients who underwent Nichols' technique, against the 14.3\% found in the other group, with a statistically significant difference $(p<0.01)$. By contrast, the anatomic correction of vaginal profile did not result significantly different in the two groups analyzed. We concluded that the four-corner procedure is more successful in terms of incontinence cure.
\end{abstract}

SUMMARY: The four-corner procedure is more successful than Nichols' technique in the surgical approach of stress urinary incontinence with large anterior prolapse.

RUNNING TITLE: Raz vs Nichols' technique in the correction of SUI with anterior prolapse. 


\section{INTRODUCTION}

Urinary incontinence in women should be correctly diagnosed, rationally evaluated, and properly treated, according to the kind of incontinence. In stress urinary incontinence (SUI), the aim of the therapeutical approach is to obtain an objectively demonstrable urinary continence, maintaining a satisfactory function of bladder voiding at the same time.

Various surgical procedures have been proposed. Several authors prefer the abdominal way: the colposuspension according to Burch is widely used [1], particularly when concomitant abdominal hysterectomy has to be performed, and the successful correction rate has been reported to be 90-98\% [2, 3]. No other operations have been demonstrated to work more successfully either in randomized or non randomized comparisons [4]. However, some troublesome complications resulting from the Burch colposuspension, such as postoperative detrusor instability and voiding difficulties are described in literature [5, 6]. Moreover, this technique is not able to repair the large cystocele often associated with SUI.

A more practical solution seems to be the adoption of the transvaginal way since it also make it possible to correct the marked cystocele together with the descensus of the other segments. Such cases have been treated by anterior colporrhaphy and Kelly stitches, which in long-term follow-up studies have yielded success rates of about 60\% [7].

Some authors claim that transvaginal bladder neck suspension is the method of choice in the treatment of stress in- continence combined with uterovaginal descent. [8, 9]. The retropubic-vaginal combined way seems to be a more interesting solution, even if it is a longer and more complex surgery. Pereyra's operation and its modifications have been reported to result in success rates of 86\%-94\% [8, 9]. Four corner bladder and urethral retropubic suspension by Raz could seem to be able to correct the majority of defects (lateral defects) responsible of the anterior vaginal wall prolapse, curing the SUI at the same time. However, the suitability of this method has not been tested in a large homogeneous population of patients with simultaneous complaints of urinary stress incontinence and large anterior urethro-vaginal descent; furthermore the effectiveness of this surgical approach has not been compared to a standard surgical technique like as anterior colporrhaphy according to Nichols.

For these reasons our study aimed to compare, in a prospective randomized trial, the results, in terms of anatomic and functional correction, of two procedures of correction of SUI with cystocele 3-4 degree: four-corner bladder and urethral suspension [8] versus anterior repair according to Nichols [10].

\section{MATERIALS AND METHODS}

From June 1996 through April 2000, 80 patients affected by SUI of type 1 and 2 according to Blaivas [11] with urethrocystocele 3-4 degree, according to the halfway system proposed by Baden and Walker were enlisted [12] and attributed in a random way, with randomization $2: 1$, using the method 
of sealed envelopes, to the following treatments: 1 st - anterior colporrhaphy; 2nd -4 corner bladder and urethral suspension.

We decided to adopt a non balanced randomization (randomize 2:1) because, among the authors, all were able to perform the anterior colporrhaphy (standard treatment), while only the first author (V.S. P.) was able to perform the 4 corner procedure. The sealed envelopes were opened the day before surgery.

The study protocol was previously approved by local Ethical committee. Each patient gave written informed consent before entry into the study.

The anterior colporrhaphy was performed according to Nichols' technique [10]. The second treatment was performed according to four-corner bladder and urethral suspension technique, introduced by Raz in 1989 [13-15].

The only difference we introduced was that inside the spiral suture a thin polypropylene mesh was incorporated in order to strengthen the support of ligature.

Before surgery, patients underwent a complete urogynecological work-up including: - vaginal profile with evaluation of kind of vaginal defect (apical, central, lateral); - Q-tip test; - Stress test (with $300 \mathrm{ml}$ in clino and orthostatism); - Pad test (evaluation after 1 hour); - urodynamic examination.

In this study, patients with irritative voiding symptoms (frequency and urgency) and patients with mixed incontinence (stress and urgency) were also included. If urgency was considered to be the primary component of the overall incontinence of the patient, a trial bladder retraining (timed voiding,
Kegel exercises and fluid restriction) and anticholinergic drugs was instituted. In this subgroup surgery was performed if stress urinary incontinence still theprominent symptom despite these conservative measures.

When necessary some patients underwent hysterectomy and correction of enterocoele and rectocele.

Time of surgery, days of hospital stay, intraoperative and postoperative complications have been recorded.

Postoperative follow-up was recorded from outpatients examinations. Follow-up evaluations included: history, physical examination for assessment of vaginal wall prolapse and persistent stress urinary incontinence. Repeated urodynamic evaluations were reserved for failed cases, or for patients with significant de novo obstruction or urgency symptoms. Our followup protocol after the initial postoperative visit consisted of outpatient visits at 1,3 , and 6 months, every 6 months for the following 2 years and then yearly.

At the follow-up examination those patients who had no urine loss during the stress test with $300 \mathrm{ml}$ in clino and orthostatism were considered as recovered. Besides, it the descensus of anterior and posterior segments was also revalued according to the halfway system.

The last follow-up was carried out in January 2001.

All results are expressed as mean \pm $\mathrm{SD}$ or as percentage. Data were stored and analyzed with the use of SPSS release 5.0 (SPSS Inc., Chicago, IL) on an IBM-compatible computer. Statistical analysis was performed by Student's t test; qualitative variables were assessed by two-tailed c2 test. The probability 
of relapse was evaluated with the Logrank test. A p value $<0.05$ was considered statistically significant.

\section{RESULTS}

The follow-up time of the patients under study varied from 280 to 1670 days. Patients assigned to the 1 st group (52) had a mean age of 59.8 years (range: 41-79 years), while those assigned to the 2nd group (28) had a mean age of 60.6 years (range: 39-78 years) $(p=N S)$. Between the two groups there was no significant difference in terms of dysmetabolic diseases (i.e., diabetes) and pathologies of the respiratory tract.

The obstetrical history of the two groups was not significantly different: the mean number of pregnancies resulted to be 3.2 with parity 2 in the first group versus an average of 3.5 and 2.5 respectively in the second group.

Forty-seven patients out of 52 in the first group and $26 / 28$ patients in the second group underwent a contemporary vaginal hysterectomy $(\mathrm{p}=\mathrm{NS})$.

SUI relapse occurred in 14 out of 52 patients who had undergone Nichols' procedure (26.9\%), and in 4 out of 28 women (14.3\%) in the 4 corner group, with a statistically significant difference between the two groups $(\mathrm{p}<0.01)$. Figure 1 graphically represents the probability of relapse over time, which underlines the worse trend for patients who underwent Nichols' procedure compared to those

Figure 1 - Probability of relapse, evaluated with the Log-rank test, in the two groups studied

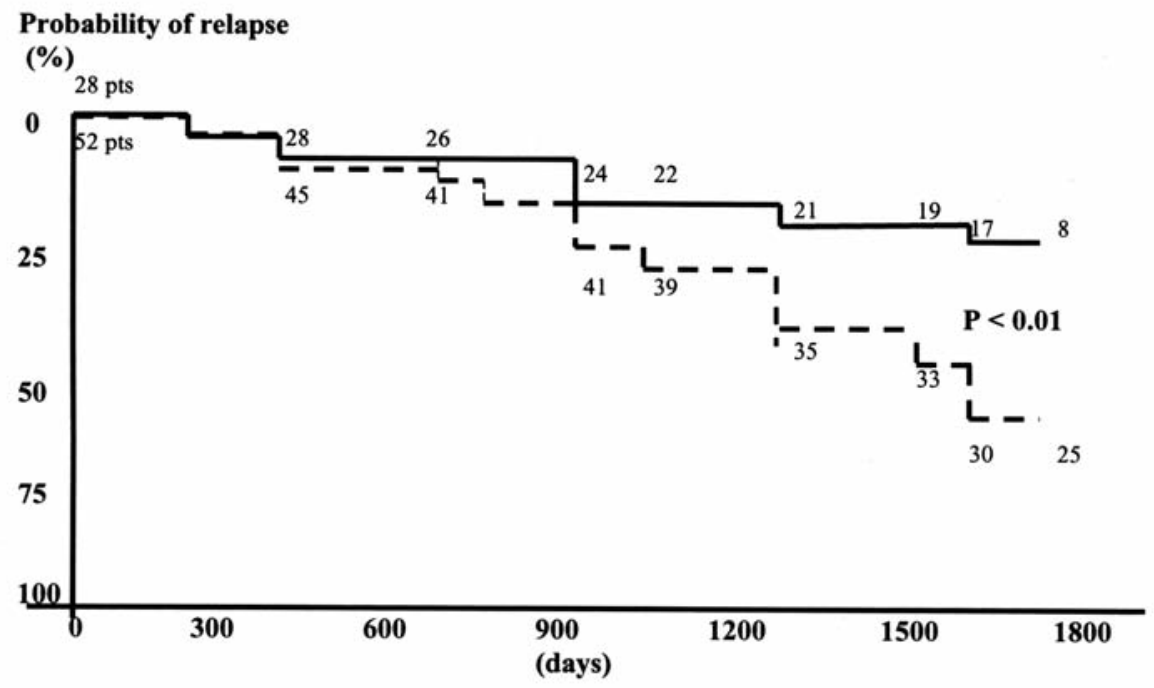

Nichols: _ _ _ ; 4 Corner: 
treated with the 4 corner procedure. Figure 1 is also reports the number of analyzed patients at different trial times.

No difference in the distribution of kind of cystocele (lateral, central or apical) was present at the moment of the enrolment between the two groups studied. Table 1 reports pre and postoperative mean vaginal profiles (VP) 1 (urethrocele) and VP 2 (cystocele) of the two groups. As far as the degree of pre and postoperative urethrocele is concerned, there is no difference in the two groups. At the sixth month analysis, the anatomic correction of cystocele resulted to be significantly better $(\mathrm{p}=0.01)$ in the 2 nd group ( 4 corner) compared to the 1 st one (Nichols). In the last follow-up visit, there was a trend toward a better VP 2 in the 2 nd group when compared to the first one, even if the difference was no longer significant .

At the sixth month analysis, a de novo 3 rd degree rectocele occurred in 3 patients (5.8\%) in the Nichols' group and in the last follow-up visit remained the same. By contrast, in the 4 corner group, the rectocele of 3 rd degree, with or without enterocoele, occurred in a higher number of cases $(5$ pts, $17.9 \%$ ), in the first follow-up visit, while a clear improvement of the posterior vaginal profile was noticed in the last follow-up visit, since 3 rd degree rectocele occurred in only 2 cases (7.1\%) (Table 2).

Data concerning preoperative urge incontinence, 1st, 2nd, and 3 rd follow-

Table 1 - Preoperative and postoperative evaluation of anterior vaginal wall defects in the two groups studied, according to the "balfway system"

\begin{tabular}{lccc}
\hline \multicolumn{1}{c}{ VP \# } & \multicolumn{2}{c}{ Technique of surgery } & Significance \\
\hline Nichols & 4 Corner & p \\
\hline VP 1 post 1 & 3.04 & 3.01 & $\mathrm{NS}^{*}$ \\
\hline VP 1 post 2 & 1.06 & 1.00 & $\mathrm{NS}^{*}$ \\
\hline VP 2 pre & 1.21 & 1.18 & $\mathrm{NS}^{*}$ \\
\hline VP 2 post 1 & 3.48 & 3.68 & $\mathrm{NS}^{*}$ \\
\hline VP 2 post 2 & 1.21 & 0.9 & 0.01 \\
\hline
\end{tabular}

* NS= not significant.

\# VP= vaginal profile.

VP 1 and 2 pre are evaluated before surgery.

VP 1 and 2 post 1 are evaluated at the sixth month postoperative follow-up.

VP 1 and 2 post 2 are evaluated at the last follow-up (January 2001). 
up visits, as well as the frequency of irritative voiding symptoms in the analyzed groups are expressed in Table 3 . Surgery had a significant effect in decreasing irritative voiding symptoms in all categories (frequency, urgency, and urge incontinence). Urge incontinence, which before surgery was present in $50 \%$ of patients treated with the 4 corner technique, decreased to $14.3 \%$ in postoperative period (after 1 month), remained on these values in the 2 nd follow-up visit (after 6 months) and slightly increased (17.8\%) in the last follow-up visit.

Patients who underwent Nichols' surgery had a different course. The number of women affected by urge incontinence before the surgery was little smaller $(42.3 \%)(\mathrm{p}=\mathrm{NS})$. The improvement at the 1 st and 2 nd follow-up was progressive and more evident. However, in the last follow-up visit, symptoms came back to several patients who lost the temporary improvement recorded in the 2 nd follow-up and returned to the values of the first follow-up visit (23.1\%).

The postoperative stay in hospital was slightly longer for the 4 corner (mean stay was 5 days with a range between 4 and 34 days vs mean stay of 6 days, with a range between 4 and 20 days in the first group; $\mathrm{p}=\mathrm{NS}$ ). Eight women $(15.4 \%)$ in the 1 st group and $10(35.7 \%)$ in the 2nd one had an hospital stay of more than six days.

Spontaneous micturition (with postmicturition residue $<50 \mathrm{ml}$ ) occurred on average in 3.62 days (with a range variable from 2 to 9 days) in the 1 st group vs 4.78 in the 2 nd group (range:

Table 2 - Postoperative evaluation of posterior vaginal wall defects in the two groups under study, according to the "halfway system".

\begin{tabular}{ccccc}
\hline \multicolumn{5}{c}{ Postoperative Rectocele } \\
\hline Degree & $\begin{array}{c}\text { Post 1 } \\
\mathrm{N}^{\circ} \text { pts }(\%)\end{array}$ & $\begin{array}{c}\text { Post 2 } \\
\mathrm{N}^{\circ} \text { pts }(\%)\end{array}$ & $\begin{array}{c}\text { Post 1 } \\
\mathrm{N}^{\circ} \text { pts }(\%)\end{array}$ & $\begin{array}{c}\text { Post 2 } \\
\mathrm{N}^{\circ} \text { pts }(\%)\end{array}$ \\
\hline Absence & $39(75)$ & $38(73.1)$ & $10(35.7)$ & $10(35.7)$ \\
\hline I & $8(15.4)$ & $9(17.3)$ & $6(21.4)$ & $11(39.2)$ \\
\hline II & $2(3.8)$ & $2(3.8)$ & $6(21.4)$ & $4(14.3)$ \\
\hline II + enterocoele & $3(5.8)$ & $3(5.8)$ & $4(14.3)$ & $1(3.6)$ \\
\hline III + enterocoele & 0 & 0 & $1(3.6)$ & $1(3.6)$ \\
\hline
\end{tabular}

Post 1: evaluation at the sixth month;

Post 2: evaluation at the last follow-up (January 2001). 
3-9 days) ( $p=$ NS). One patient $(1.9 \%)$ in the 1 st group and one (3.6\%) in the 2 nd one had urinary retention ( $>5$ days and $<10$ days).

A woman of the 4 corner group had a retropubic sepsis that required the removal of stitches and a long hospital stay.

\section{DISCUSSION}

We compared two different techniques of correction of SUI with $3^{\circ}-4^{\circ}$ degree urethrocystocele: anterior colporrhaphy according to Nichols versus 4 corner bladder and urethral suspension according to Raz. Our data show that 4 corner procedure determines better results.

Since relapses occur at different times and they are noticed during follow-up controls, in order to compare the results of the two surgeries in terms of SUI correction, we used the log-rank test to calculate the probability of relapse during the time. In the follow-up visit carried out in January 1999, although statistically not significant, it was already evident that one of the two procedures ( 4 corner) had considerably less possibilities of relapse compared to the other one. In the follow-up visit, performed in January 2000, the difference between the two groups acquired significance $(\mathrm{p}<0.01)$, confirming this course. At the last follow-up control the SUI relapse occurred in $26.9 \%$ of patients who underwent Nichols' surgery versus the $14.3 \%$ of the other group with a statistically significant difference $(\mathrm{p}<0.01)$.

The causes of recurrent stress urinary incontinence after a period of clinical cure may be various. Certainly failure from either suture breakage or erosion of the paraurethral tissues is the most common cause. Factors that may predispose to recurrent stress incontinence include the type of suture material (absorbable material has a higher tendency to fail), quality of the tissues that are incorporated in the sus-

Table 3 - Preoperative and postoperative evaluation of irritative voiding symptoms (urgency and/or urge incontinence and frequency) in the two groups studied.

\begin{tabular}{|c|c|c|c|c|c|c|c|c|}
\hline \multicolumn{6}{|c|}{ URGENCY AND/OR URGE INCONTINENCE(\%) } & \multicolumn{3}{|c|}{ FREQUENCY (\%) } \\
\hline & $\begin{array}{c}\text { PRE } \\
\% \\
\left(\mathrm{~N}^{\circ} \mathrm{pts}\right)\end{array}$ & $\begin{array}{c}\text { Post } 1 \\
\% \\
\left(\mathrm{~N}^{\circ} \mathrm{pts}\right)\end{array}$ & $\begin{array}{c}\text { Post } 2 \\
\% \\
\left(\mathrm{~N}^{\circ} \mathrm{pts}\right)\end{array}$ & $\begin{array}{c}\text { Post } 3 \\
\% \\
\left(\mathrm{~N}^{\circ} \mathrm{pts}\right)\end{array}$ & $\begin{array}{c}\text { Pre } \\
\% \\
\left(\mathrm{~N}^{\circ} \mathrm{pts}\right)\end{array}$ & $\begin{array}{c}\text { Post } 1 \\
\% \\
\left(\mathrm{~N}^{\circ} \mathrm{pts}\right)\end{array}$ & $\begin{array}{c}\text { Post } 2 \\
\% \\
\left(\mathrm{~N}^{\circ} \mathrm{pts}\right)\end{array}$ & $\begin{array}{c}\text { Post } 3 \\
\% \\
\left(\mathrm{~N}^{\circ} \mathrm{pts}\right)\end{array}$ \\
\hline Nichols & $\begin{array}{c}42.3 \\
\text { (22 pts) }\end{array}$ & $\begin{array}{c}23.1 \\
\text { (12 pts) }\end{array}$ & $\begin{array}{c}7.7 \\
\text { (4 pts) }\end{array}$ & $\begin{array}{c}23.1 \\
\text { (12 pts) }\end{array}$ & $\begin{array}{c}23.1 \\
\text { (12 pts) }\end{array}$ & $\begin{array}{c}13.5 \\
\text { (7 pts) }\end{array}$ & $\begin{array}{c}26.9 \\
\text { (14 pts) }\end{array}$ & $\begin{array}{c}19.3 \\
\text { (10 pts) }\end{array}$ \\
\hline 4 corner & $\begin{array}{c}50 \\
\text { (14 pts) }\end{array}$ & $\begin{array}{c}14.3 \\
\text { (4 pts) }\end{array}$ & $\begin{array}{c}14.3 \\
(4 \mathrm{pts})\end{array}$ & $\begin{array}{c}17.8 \\
(5 \mathrm{pts})\end{array}$ & $\begin{array}{c}25 \\
(7 \mathrm{pts})\end{array}$ & $\begin{array}{c}14.3 \\
(4 \mathrm{pts})\end{array}$ & $\begin{array}{c}10.7 \\
\text { (3 pts) }\end{array}$ & $\begin{array}{c}7.1 \\
\text { (2 pts) }\end{array}$ \\
\hline
\end{tabular}

Pre: before surgery;

Post 1: the first month postoperative follow-up;

Post 2: the sixth month postoperative follow-up;

Post 3: the last postoperative follow-up (January 2001). 
pension and unusual physical stresses (chronic coughing or obesity). If the patient with poor support has persistent stress incontinence, probably the sutures were never properly placed in the paraurethral tissues surrounding the bladder neck. Rarely, the sutures may not have been tied with enough tension [16].

At the sixth month postoperative follow-up the anatomic correction of cystocele had resulted significantly better in the 4 corner group. The reasons of this result are probably both the fact that the Raz procedure causes an overcorrection of the anterior segment and that the cystocele has a double component (one of central type and one of lateral type) and the latter procedure corrects both defects, while medialization surgeries of the fascia only correct the central defect when it is present [17, 18]. However, some authors disagree with the use of Raz technique, because they think that this kind of repair does not approximate anatomic tissues in proper relation, but suspends the anterior vaginal wall, thus disrupting the rather horizontal axis of the proximal two thirds of the vaginal tube and that this may predispose to iatrogenic vault prolapse or enterocele formation, as it has been described after the Burch procedure [18-20]. In our study, we found that the over-correction of the anterior segment, carried out with this kind of technique, causes a modification of lines of force and pelvic statics, bringing about a higher number of posterior segment prolapses; however, we also noticed that, with the passing of time, this action looses its significance, as if the forced correction of the anterior segment caused by the Raz surgery lessens in the course of time and subsequently improves the statics and distribution of lines of force on the pelvic floor. In this way, the clear improvement of posterior vaginal profile with the subsequent decrease of rectocele noticed in this group of patients at the last follow-up can be explained.

The technique of paravaginal defect repair restoring the normal lateral attachment of the pubocervical fascia to the arcus tendineous fascia pelvis of the pelvic sidewall and providing anatomic repair of lateral cystoceles, probably guarantees better results when, as actually occurs in $85-90 \%$ of cases [17], the cystocele has an exclusively lateral component. However, the surgical technique for performing the paravaginal defect repair, as described by Richardson et al. [21], involves a Pfannestiel or a low midline incision and this represents a discomfort for the patient, particularly when the surgery is associated to other corrections of vaginal vault prolapse carried out through the vagina (for example, hysterocele, enterocele, and rectocele).

Besides, the results published by Bruce et al in 1999 [18] concerning a sample of 77 patients with cystocele by lateral defect associated to urinary incontinence of type 1 (52 patients) and 2 (27 patients) treated with Richardson's technique are not very different from those obtained in our study. At a mean follow-up of 17 months, the cure rate, defined as no pads and no leakage was 79\%. When expanded to include substantially improved patients ( $1 \mathrm{pad} /$ day or less) the success rate was $84 \%$. In our study, at the last follow-up, the Raz technique presented a SUI cure rate of $85.6 \%$. 
To obtain best results with the minimum discomfort for the patient in case of descent of the anterior segment associated to a SUI type 1 and 2, the paravaginal repair defect should probably be carried out through the vagina, as proposed by Benson and co-workers. Actually the authors did not present encouraging results in their series. However, it should be highlighted that there are some flaws in the experimental design. Indeed in all patients who underwent vaginal paravaginal repair a sacrospinous colpopexy was also performed [22]. It is ascertained that this surgical procedure is responsible for an increased risk of cystocele as well as for an abnormal opening of the urethrovesical angle thus leading to SUI [23].

The effect of bladder neck suspension on irritative voiding symptoms has received considerable interest in the past decades [11, 16, 24-26]. In our study Nichols' surgery does not substantially modify the symptom of frequency, whereas, it causes a clear improvement of urgency. This improvement is temporary, as shown by the de novo development of urge incontinence at the last follow-up in a $23,1 \%$ of patients. This could be explained observing that the procedure of vagina blunt dissection passes in the interstitial stratum between the vaginal visceral fascia and vaginal septum, causing a vesical denervation that, however, in the course of time, disappears. On the other hand the Raz procedure causes a progressive improvement of the fre- quency symptom, with a remission of symptomatology at the last control in more than $75 \%$ of the cases. Besides, our data clearly suggest that when urge incontinence is combined with subjective and objective anatomical stress incontinence, bladder neck suspension will cure the symptoms of urge incontinence in more than $50 \%$ of the cases. The mechanism by which bladder neck suspension improves or cures urge incontinence is unclear but a possible explanation is that the urine in the incompetent posterior urethra facilitates the reflex contraction of bladder. The bladder neck suspension, by closing and helping to coapt the posterior urethra, may eliminate this reflex facilitation.

A last consideration to be made is that all anti-incontinence procedures cause a potential risk of urinary retention or obstructive symptomatology. On the other hand, according to our experience, we only ran into transitory urinary retentions, in a very low percentage of cases. Neither procedures ever caused permanent urinary retention (> 10 days).

According to the results of our study, we can conclude that the 4 corner technique has much more possibilities of lasting success concerning continence, guaranteeing security and applicability in case of coexistent descensus of the anterior vaginal segment of moderate or severe degree. Relapses in posterior segments represent a transitory accident that tends to decrease over time.

\section{CORRESPONDING AUTHOR:}

VINCENZO SCOTTO DI PALUMBO, M.D.

VIA J.F. KENNEDY, 02100 RIETI - ITALY - TELEPHONE NUMBER: 0746278269 - 337747818

FAX NUMBER 0746278497 - E-MAIL: VINCENZOSCO@TISCALI.IT 


\section{References}

1 - PENTTINEN J., KAAR K., KAUPPILA A. : Colposuspension and transvaginal bladder neck suspension in the treatment of stress incontinence.

Gynecol Obstet Invest 1989; 28 (2):101-5.

2 -GREEN D.F., McGUIRE E.J., LYTTON B. : A comparison of endoscopic suspension of the vesical neck versus anterior urethropexy for the treatment of stress urinary incontinence.

J Urol 1986; 136:1205-7.

3 -PETTINEN J., KAAR K., KAUPPILA A. :

Effect of suprapubic operation on urethral closure function evaluated with single cough urethrocystometry with computer-connected multitransducer catheter.

Br J Urol 1989; 63:389-91.

4 -COLOMBO M., MILANI R., VITOBELLO D., MAGGIONI A. : A randomized comparison of Burch colposuspension and abdominal paravaginal defect repair for female stress urinary incontinence. Am J Obstet Gynecol 1996; 175:78-84.

5 - VIERHOUT M.E., MULDER A.F.P. :

De novo detrusor instability after Burch colposuspension.

Acta Obstet Gynecol Scand 1992; 71: 414-6.

6 -LOSE G., JORGENSEN L., MORTENSEN S.O., MOLSTED-PEDERSEN L., KRISTINSEN J.K. :

Voiding difficulties after colposuspension.

Obstet Gynecol 1987; 69: 33-7.

7 - RIGGS J.A. :

Retropubic cystourethropexy: a review of two operative procedures with longterm follow-up.

Obstet Gynecol 1986; 68: 98-105.

8 - RAZ S. :

Modified bladder neck suspension for female stress incontinence.

Urology 1981; 17:82-5.

9 -FOWLER J.E. Jr. :

Experience with suprapubic vesicourethral suspension and endoscopic suspension of the vesical for stress urinary incontinence in females.

Surg Gynecol Obstet 1986; 162:437-41.

10 - NICHOLS D.H., MILLEY P.S. :

Identification of pubourethral ligaments and their role in transvaginal surgical correction of stress incontinence.

Am J Obstet Gynecol 1973; 115: 123-8.

11 -BLAIVAS J.G., OLSSON C.A. :

Stress incontinence: classification and surgical approach.

J Urol 1988; 139:727-31. 
12 -BADEN W.B., WALKER T. :

Surgical repair of vaginal defects.

Philadelphia: Lippincott, 1992.

13 -RAZ S., GOLOMB J., KLUTKE C. :

Four-corner bladder and uretbral suspension for moderate cystocele.

J Urol 1989; 142:712-5.

14 -RAZ S. :

Vaginal surgery for stress incontinence.

J Am Geriatr Soc 1990; 38 (3): 345-7.

15 -RAZ S., LITTLE N.A., JUMA S., SUSSMAN E.M. :

Repair of severe anterior vaginal wall prolapse (grade IV cystourethrocele).

J Urol 1991; 146 (4):988-92.

16 -RAZ S., SUSSMAN E.M., ERICKSON D.B., BREGG K.J., NITTI V.W. :

The Raz bladder neck suspension: results in 206 patients.

J Urol 1992, 148:845-50.

17 -RICHARDSON A.C., EDMONDS P.B., WILLIAMS N.L. :

$A$ new look at pelvic relaxation.

Am J Obstet Gynecol 1976; 126:568-71.

18 -BRUCE R.G., EL-GALLEY R.E., GALLOWAY N.T. :

Paravaginal defect repair in the treatment of female stress urinary incontinence and cystocele.

Urology 1999; 54 (4):647-51.

19 -BURCH J.C. :

Urethrovaginal fixation to Cooper's ligament for correction of stress

incontinence, cystocele and prolapse.

Am J Obstet Gynecol 1961; 81:281-4.

20 -BURCH J.C. :

Cooper's ligament urethrovesical suspension for stress incontinence.

Am J Obstet Gynecol 1968; 100:764-74.

21 -RICHARDSON A.C., EDMONDS P.B., WILLIAMS N.L. :

Treatment of stress urinary incontinence due to paravaginal fascia defect.

Obstet Gynecol 1981; 57:357-60.

22 -BENSON J.T., LUCENTE V., MCCLENNAN E. :

Vaginal versus abdominal reconstructive surgery for the treatment of pelvic support defects: a prospective randomized study with long-term outcome evaluation.

Am J Obstet Gynecol 1996; 175:1418-22.

23 -NICHOLS D.H., RANDALL C.L.:

Vaginal Surgery.

Third Ed., Baltimore, Williams \& Wilkins 1989.

24 -Mc GUIRE E.J., SAVASTANO J.A. :

Stress incontinence and detrusor instability/urge incontinence.

Neurourol Urodynam 1985; 4:313-17. 
25 -CARDOZO L.D, STANTON S.L. :

Genuine stress incontinence and detrusor instability-review of 200 patients. Br J Obstet Gynaec 1980; 87:184-90.

26 -CARDOZO L.D., STANTON S.L., WILLIAMS J.E. :

Detrusor instability following surgery for genuine stress incontinence.

Br J Urol 1979; 51:204-7. 